\title{
L La crítica \\ a la modernidad en \\ Dialéctica de la ilustración
}

\section{Aldo Rabiela Beretta' Alice Salomon Hochschule Berlin}

Resumen: A lo largo de este ensayo me propongo reconstruir el argumento crítico que Horkheimer y Adorno elaboraron en Dialéctica de la ilustración, y esbozar su relación con la modernidad capitalista. En continuidad con las interpretaciones de Jürgen Habermas, Axel Honneth y Bolivar Echeverría muestro, en primer lugar, que el argumento crítico de Dialéctica de la ilustración identifica la presencia de una forma de relación particular con los otros y con el mundo. En segundo lugar, muestro que esta forma de relación surge como resultado del predominio de un modo de pensar y un modo de actuar orientado por los principios de la ilustración. Por último, indico que este modo de pensar y de actuar conforma una habituación social al modo de una segunda naturaleza que restringe la capacidad de su transformación y crítica.

Abstract: Throughout this essay, I pursue to reconstruct the critical argument that Horkheimer and Adorno developed in Dialectic of Enlightenment and outline its relationship to capitalist modernity. In accordance with the interpretations of Jürgen Habermas, Axel Honneth and Bolivar Echeverría, I show that the critical argument in Dialectic of Enlightenment identifies a specific kind of relationship with the others and the world. Secondly, I demonstrate that this kind of relationship emerges as a result of a mode of thought and action guided by the principles of Enlightenment. Finally, I indicate that this mode of thought and action shapes a social habituation - as a second nature-, that restricts the capability of its transformation and critique.

Palabras clave: Adorno, Horkheimer, Modernidad, Capitalismo, Escuela de Franfurt, Teoría crítica

Keywords: Adorno, Horkheimer, Modernity, Capitalism, Frankfurt School, Critical Theory 
La obra emblemática de la primera generación de la Escuela de Frankfurt, Dialéctica de la ilustración, es un texto que con el paso del tiempo corre el riesgo de perder vigencia. Sus ensayos comprendidos como una interpretación sobre la modernidad desde el plano de la antropología filosófica han sido teóricamente puestos en entre dicho. Sin embargo, como lo ha señalado Axel Honneth, es posible recuperar cierta actualidad de la obra si investigamos el motivo crítico que la conforma. Orientado por dicha intención, en este ensayo ${ }^{2}$ presento una reconstrucción inicial del argumento crítico de Dialéctica de la ilustración y, a su vez, esbozo su relación con la modernidad capitalista. Apoyado en las investigaciones de Axel Honneth, Jürgen Habermas y Bolívar Echeverría, abordo el tema en cinco apartados. El primero investiga el modo de crítica inmanente que Adorno y Horkheimer desarrollan a lo largo de su obra. El segundo apartado analiza el objeto de la crítica entendido como las aporías que contiene el pensamiento ilustrado. El tercer apartado indica el modo de relación que el pensamiento ilustrado constituye ante la naturaleza externa e interna, como una forma de vinculación específica que cobra predominio en la modernidad. El cuarto apartado ofrece una explicación sobre la generalización de esta forma de vinculación que ocurre a través de la organización social capitalista y las consecuencias que ello conlleva para la crítica. Por último, el quinto apartado presenta -a modo de conclusión- el rumbo que adquiere la crítica a la modernidad capitalista desde la reconstrucción propuesta.

\section{Crítica inmanente}

Dialéctica de la ilustración está compuesta por un ensayo central sobre el concepto de ilustración, dos excursos y tres apéndices que representan más de la mitad de la obra en su conjunto. ${ }^{3}$ En la apelación a los términos fragmentos filosóficos, en el subtítulo de Dialéctica de la ilustración, se apunta al tipo de discurso que Adorno y Horkheimer tienen en mente. Resulta innegable que la forma de exposición que caracteriza a la obra no ofrece un acceso directo a la secuencia del argumento crítico, ni permite reconocer a primera vista su estructura. ${ }^{4}$

Sin embargo, siguiendo a Honneth, considero que la estrategia argumentativa de la obra tiene por objetivo poner en cuestión la familiaridad de nuestro trato con el mundo para descubrir "las pre-condiciones bajo las cuales los discursos evaluativos sobre los fines de la acción común son conducidos en una sociedad" (Honneth, 2000, p. 71). De este modo, el argumento 
crítico de Dialéctica de la ilustración no pretende ofrecer una interpretación alternativa de la historia de la especie humana, sino más bien tiene el propósito de provocar una ruptura con la percepción habitual sobre el mundo de la vida ${ }^{5}$ para revelar su carácter aporético, respecto a los propios criterios que éste ha establecido para sí mismo. Lo anterior, en continuidad con la tradición de la crítica de la economía política, particularmente expresada en el tercer apartado del "Cuaderno M" intitulado Introducción general a la crítica de la economía política, ${ }^{6}$ donde Marx señala que las categorías económicas expresan determinaciones de existencia y formas de $\operatorname{ser}^{7}$ que han de ser develadas.

Wellmer coincide en el sentido general de la afirmación previa cuando señala que Adorno y Horkheimer plantean en Dialéctica de la ilustración "las consecuencias de su interpretación crítica de Marx y de sus nuevas experiencias históricas" (Wellmer, 1973, pp.137-138). Esto significa -para el filósofo de la segunda generación de la Escuela de Frankfurt- que la obra se inscribe en una renovada crítica a la economía política en la que ya no se entiende a ésta última como el ámbito fundamental donde yace la aporía de la modernidad, sino que ahora la economía política se concibe sólo como el plano que expresa y actualiza el nuevo ámbito que Adorno y Horkheimer habrían revelado. Esto es, en un tipo de racionalidad que se encuentra en el origen del proceso civilizatorio, ${ }^{8}$ y más precisamente en la separación entre ser humano y naturaleza efectuada por medio de la reflexión conducida por los imperativos prácticos de la autoconservación.

El argumento crítico de Dialéctica de la ilustración se distingue por contener un carácter inmanente, debido a que la instancia que otorga validez a la crítica es el contenido normativo perteneciente al concepto -en este caso- de pensamiento ilustrado. Como indican Horkheimer y Adorno en uno de los esbozos del tercer apéndice intitulado "Filosofía y división del trabajo": la libertad de la filosofía frente a la sugestión de lo existente yace en que acepta que los ideales modernos, a pesar de su deformación y manipulación, aún son reconocibles como sentido objetivo de las instituciones. ${ }^{9}$ De este modo, la crítica pretende obtener su validez al develar no sólo los efectos del uso de un concepto, sino los elementos inmanentes al concepto y a su realización que se contraponen. Lo anterior concibe a la crítica como un tipo de negación determinada que presupone la idea de una contradicción al interior de las nociones y en su realización práctica.

Justamente para Horkheimer y Adorno: 
(L)a negación determinada rechaza las representaciones imperfectas del absoluto, los ídolos, no como el rigorismo oponiéndoles la idea que no pueden satisfacer. La dialéctica revela más bien toda noción como escritura. Ella enseña a leer en sus rasgos la confesión de su falsedad, le arrebata (a toda noción) su poder y se lo dedica a la verdad. (Horkheimer/Adorno, 2003, pp. 46-47)

En este esbozo de lo que los autores comprenden por negación determinada considero que es posible conocer una síntesis de la estrategia crítica que precisamente asume Dialéctica de la ilustración frente a la modernidad.

Ahora bien, para reconstruir la crítica que enmarca la obra recuperaré un par de declaraciones centrales hechas por los autores en el prólogo de 1944. En primer lugar, Horkheimer y Adorno señalan: "(l)o que nos habíamos propuesto era de hecho nada menos que la comprensión de por qué la humanidad, en lugar de ingresar en un estado verdaderamente humano, se hunde en un nuevo tipo de barbarie" (Horkheimer/Adorno, 2003, p. 16). Y en segundo lugar resuelven que:

La aporía frente a la que nos encontramos en nuestro trabajo se mostró por consiguiente como el primer objeto que tuvimos que investigar: la autodestrucción de la ilustración. No albergamos ninguna duda -y en esto yace nuestra petitio principiique la libertad en la sociedad es inseparable del pensamiento ilustrado. Sin embargo, nosotros creemos haber comprendido igual de claro, que justamente el concepto de este pensamiento, no menos que sus formas históricas concretas, las instituciones de la sociedad en las que está entretejido, contienen ya el germen hacia aquel retroceso que hoy se produce por todas partes. (Horkheimer/Adorno, 2003, p. 18)

La primera afirmación que observamos acusa dos elementos críticos. Uno de ellos es comprender por qué la humanidad se hunde en un nuevo tipo de barbarie, y el otro es comprender por qué ocurre esto en lugar de entrar en un estado verdaderamente humano como lo prometía el pensamiento ilustrado.
Ambos elementos anuncian la inviabilidad entre dos alternativas opuestas en términos de aporía. La segunda afirmación sugiere la dirección por donde buscarán la respuesta para revelar esta inviabilidad. Esto es, que la ilustración se autodestruye, y que el germen de dicha autodestrucción está 
presente en el concepto de pensamiento ilustrado y en las instituciones en que está entretejido, pero al mismo tiempo reitera la inviabilidad entre las alternativas que el pensamiento ilustrado promete entre las antípodas de libertad y retroceso.

Como indica Wiggershaus, tanto Horkheimer como Adorno en un principio:

Habian sido entusiastas partidarios de la ilustración -Horkheimer, de la ilustración francesa, como desenmascaramiento de la hipocresía y la injusticia sociales, Adorno de la ilustración y el esclarecimiento de todo lo pulsional, oscuro, enmohecido, inconsciente; ambos de la revelación marxiana de las condiciones económico-sociales de la emancipación humana. (Wiggershaus, 1986, p. 365)

Prueba de ello es que en la presentación del proyecto de investigación sobre antisemitismo que apareció en 1941 en la revista Studies in Philosophy and Social Sciences -que Horkheimer editaba desde Norteamérica como continuación de la Zeitschrift für Sozialforschung- se presentó una noción positiva del pensamiento abstracto que será posteriormente una de las dimensiones del pensamiento ilustrado abordadas críticamente en Dialéctica de la ilustración.

Específicamente, se indicó en aquella publicación que:

(l)a homogeneización que resulta del pensamiento abstracto es un pre-requisito para el desarrollo del mundo en un sentido verdaderamente humano, pues este tipo de pensamiento libera a las relaciones y cosas humanas de sus tabúes, y las conduce al reino de la razón. (Studies in Philosophy and Social Sciences, 1941, p. 139, en Wiggershaus, 1986, p. 365).

Lo anterior permite observar que el propósito crítico de Dialéctica de la ilustración, como se declara por los autores en su petición de principio expresada en el prólogo de 1944, no partía de un rechazo romántico a la ilustración, sino que provenía del desconcertante descubrimiento de su carácter

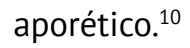

En continuidad con lo anterior observamos que las primeras dos afirmaciones del estudio inicial que compone Dialéctica de la ilustración presentan la aporía de manera prácticamente analítica. 
Desde siempre la ilustración ha perseguido, en el más amplio sentido del pensamiento progresista, el objetivo de apartar a los seres humanos del miedo y constituirlos en señores. Pero la tierra enteramente ilustrada brilla bajo el signo de una triunfal desgracia. (Horkheimer/Adorno, 2003, p. 25)

En este señalamiento, el contrasentido es entendido como aporía, pues el motivo de apartar a los seres humanos del miedo ha logrado justamente lo opuesto.

Asimismo, el interés por devenir señores de la naturaleza vinculado al pensamiento ilustrado introduce el problema de la reconceptualización de la relación entre ser humano y naturaleza como aspecto central. Pues a diferencia del concepto utilizado por la tradición de la antigüedad griega, el pensamiento ilustrado presenta una distancia entre subjetividad y naturaleza, y comprende al concepto de naturaleza básicamente como materia estructurada por leyes cognoscibles. ${ }^{11}$ Ello indica que el concepto de naturaleza reformulado en la ilustración se encuentra determinado por el criterio de utilidad, en tanto está orientado a comprender las funciones de aquello que enuncia para servicio de los fines y propósitos humanos. En esta misma línea de argumentación es posible indicar que "el criterio de utilidad se tornará, como señaló Hegel, en la ética de la ilustración" (Held, 1980, p. 153).

\section{Aporías en el pensamiento ilustrado}

En esta revisión crítica del pensamiento ilustrado, Horkheimer y Adorno descubren que el replanteamiento implícito de la relación entre ser humano y naturaleza evoca una ruptura producida por el proceso de abstracción. La abstracción conlleva un proceso de homogenización que se distingue por dominar a los objetos que involucra a través de subsumir su alteridad en una forma que los vuelve manipulables.

De este modo:

(L) a abstracción (...) se comporta respecto a sus objetos (...) como liquidación. Bajo la niveladora dominación de lo abstracto, que convierte en repetible todo en la naturaleza, (...) los mismos liberados llegaron a ser finalmente aquella "tropa" (de utilidad) que Hegel designó como resultado de la ilustración. (Horkheimer) Adorno, 2003, p. 35) ${ }^{12}$ 
La manera en que Horkheimer y Adorno tratan el problema de la abstracción presenta ya un ajuste respecto a la crítica de la economía política que, no obstante, mantiene la validez del argumento respecto a la mercancía en tanto expresión histórica, pero modifica el fundamento del problema y lo coloca en las estructuras del pensamiento de un modo que no establece su origen en la forma de relación propia de la organización social capitalista. Mientras que para Marx, el proceso de abstracción - basado en la particularidad del trabajo abstracto en tanto mercancía- ${ }^{13}$ se torna en un tipo de determinación dominante de la existencia, en Dialéctica de la ilustración "(l)a abstracción del intercambio es únicamente la forma histórica en que el pensamiento identificante despliega su efecto histórico universal y determina las formas de relación de la sociedad capitalista" (Habermas, 1981a, p. 506). ${ }^{14}$ Por lo que el pensamiento mismo es ahora investigado bajo una nueva perspectiva crítica.

Dicha perspectiva es comprendida como un proceso de homogenización que subsume las particularidades de su objeto en una forma que lo torna disponible para la manipulación humana. Aquello que es referido como objeto de la abstracción es la naturaleza ${ }^{15}$ y el proceso en su conjunto es calificado de dominación. Para aclarar esta perspectiva, en el ensayo dedicado al concepto de ilustración, Adorno y Horkheimer presentan una apretada síntesis de su crítica a la forma de pensamiento Ilustrado, donde se señala que:

(E)l pensamiento, en cuyo mecanismo de coacción se refleja y prolonga la naturaleza, mediante su imparable lógica, se refleja también a sí mismo como naturaleza olvidada, como mecanismo de coacción. En efecto, la representación se torna sólo un instrumento. Los humanos se distancian de la naturaleza mediante el pensamiento, para ponerla ante sí, de tal modo que sea dominada. (Horkheimer/Adorno, 2003, pp. 62-63)

Lo anterior permite comprender que, para Adorno y Horkheimer, la reubicación del problema de la abstracción requiere - para obtener la capacidad de conformar la equivalencia en lo pensado- de un aspecto de distancia que juega un papel fundamental. Esta distancia es caracterizada como momento del proceso de pensamiento, pero el énfasis indica que el pensamiento es representado ante sí mismo extraviado de su "condición natural" e inadvertido de su carácter coactivo. La explicación de esta apretada sentencia surge cuando 
conocemos que el aspecto coactivo del pensamiento que distancia a los seres humanos de la naturaleza, genera las condiciones para que ello sea disponible y manipulable bajo un emplazamiento subordinado. Especialmente se indica que al mismo tiempo que se establece la distancia con la naturaleza se olvida la pertenencia orgánica del ser humano con el mundo simbólico y natural. De este modo, la distancia frente al mundo permite: a) emplazarlo en una relación que, b) lo hace disponible para ser manipulado, y así c) auto-afirmar al ser humano; todo ello caracterizado por un momento de olvido que refiere un ocultamiento del proceso en el que el ser humano está inserto.

Para comprender más claramente esta dimensión del argumento recurriremos a una de las referencias del segundo excurso que permite revelar la aporía del pensamiento que Horkheimer y Adorno tienen en mente. En esta pieza, los autores inician sin preámbulos con una referencia a Kant, particularmente abren el argumento del excurso desde la sentencia que el filósofo de Königsberg formula sobre la Ilustración. Esto es:

\begin{abstract}
(l)a llustración es en palabras de Kant 'la salida del humano de su autoculpable minoría de edad. La minoría de edad es la incapacidad de servirse de su entendimiento sin la dirección de otro. El entendimiento sin la dirección de otro es el entendimiento dirigido por la razón. Eso quiere decir nada más, que el entendimiento mediante la propia coherencia une los conocimientos particulares en un sistema. (Horkheimer/Adorno, 2003, p. 104)
\end{abstract}

Después del comentario que acompaña la referencia a Kant, el análisis avanza hacia el proceder del entendimiento dirigido por la razón, y señala que éste se caracteriza porque produce un orden unitario y deduce los hechos desde el conocimiento de principios, mientras que la unidad es definida por las relaciones que establecen las leyes lógicas. ${ }^{16}$ Bajo estas condiciones para Adorno y Horkheimer, la dirección de la razón es insignificante, pues su aportación se reduce a presentar "los elementos formales de una permanente conexión conceptual" (Horkheimer/Adorno, 2003, p. 105).

En este paso, el elemento crítico sobre el tipo de unidad aportada por la razón entendida como procedimiento lógico que subsume las contradicciones reales revela a Hegel en el trasfondo, ${ }^{17}$ especialmente en tanto se considera que dicha unidad formal irrumpe en la articulación ética de las formas de vida. Esta convicción de inspiración 
El sistema que yace en el significado de la llustración es la forma de conocimiento que mejor encaja con los hechos, que ayuda al sujeto más eficazmente a la dominación de la naturaleza. Sus principios son los de la auto-conservación, la minoría de edad se demuestra como la incapacidad de conservarse a sí mismo. (Horkheimer/Adorno, 2003, p. 106)

Pues muestra que la unificación formal de la reflexión se torna un instrumento que desarrolla la función de preparar al mundo eficazmente como material disponible de ser dominado, y dicha función estaría orientada implícitamente por la finalidad no cuestionada de la auto-conservación.

A pesar de ello, la aporía mantiene una tensión con el anhelo de reconciliación humana que no hace de la crítica una mera acusación externa al significado de la idea de minoría de edad, más bien parece encontrar la inviabilidad al interior de sus tendencias contrapuestas en términos de ambigüedad conceptual como se definió con el término de negación determinada. Pues mientras el anhelo de universalidad humana expresado en la idea del entendimiento guiado por la razón supone la posibilidad de una convivencia libre, el entendimiento conforma al mundo desde un esquematismo que lo reduce a material controlable.

Los conceptos de Kant son ambiguos. La razón como yo trascendental supraindividual contiene la idea de una vida libre en común (...) Ello representa la idea de la verdadera universalidad, la utopía. Al mismo tiempo, sin embargo, la razón conforma la instancia del pensamiento calculador que dispone al mundo para los fines de la auto-conservación, y no conoce otras funciones más que la preparación del objeto, de mero material sensible, a material de subyugación. (Horkheimer/Adorno, 2003, p. 106)

\section{La relación con la naturaleza interna y externa}

El argumento crítico vincula la aporía del pensamiento ilustrado con una forma de enfrentamiento hacia la naturaleza externa e interna.
Los ámbitos de este enfrentamiento se expresan en términos de relación con el mundo, con los otros y consigo mismo, pero se encuentran 
formulados bajo las nociones de naturaleza interna y externa para mantener la coherencia con el argumento desarrollado desde el plano del pensamiento ilustrado. Esta formulación se inscribe en el marco de la tradición que va de la crítica al carácter de fetiche de la mercancía a la crítica de la reificación, y es uno de los aportes interpretativos que Adorno logra con la ayuda del énfasis de Horkheimer en las limitaciones de la forma de pensamiento ilustrado representado por Kant. Pues a partir de ofrecer la idea de una forma de pensamiento restringida a un entendimiento calculador, Adorno ofrecerá uno de los aportes decisivos de Dialéctica de la ilustración, esto se expresa en: "una generalización de la crítica marxiana del capitalismo que haga posible considerar, desde la perspectiva teórica de una creciente reificación, no sólo la historia de la sociedad capita- lista-liberal, sino el curso total de la civilización" (Honneth, 1985, p. 51).

Para revelar los orígenes de la reificación en las bases mismas de la civilización occidental, los autores investigan el relato homérico de $L a$ Odisea en el primer excurso de su obra. A partir de él encuentran trazos de un elemento problemático que se hará patente en la conformación de la subjetividad moderna, esto es, el miedo al otro identificado con la naturaleza. Desde el análisis de las aventuras de Odiseo descubren que en el momento en que lo otro es resignificado como desconocido y temible, la auto-conservación introduce su justificación para reorganizar al mundo de tal manera que lo inserte en una relación de dominio funcional como elemento necesitado de control y subordinación. De esta forma, la auto-conservación acusa un modo de proceder frente a lo otro:

\begin{abstract}
(...) a partir de la anulación de la alteridad en lo otro y su conversión en un "caos" o naturaleza salvaje por conquistar y domesticar; se avanza por la afirmación del carácter absolutamente necesario de la identidad del sujeto y su cosmos, y por la subordinación de la realidad de lo otro a esa necesidad. (Echeverría, 2012, p. 51)
\end{abstract}

Para Adorno y Horkheimer, la reorganización del mundo bajo el dominio funcional que revela la figura de Odiseo muestra también que en los relatos de la antigüedad se encuentra ya en germen la estructura del enfrentamiento consigo mismo como subordinación de la propia naturaleza. El argumento lo constatamos especialmente en su interpretación acerca del modo de proceder de Odiseo cuando afirman que: 
(e)l astuto sobrevive sólo al precio de su propio sueño, que paga desencantándose de sí mismo y de las potencias exteriores. Justamente él no puede tener jamás todo; debe saber esperar siempre, tener paciencia, renunciar; no debe comer lotos ni bueyes del sagrado Hiperión, y cuando navegue a través del estrecho debe tener en cuenta las pérdidas de los compañeros que Escila le arranca de la nave. (Horkheimer/Adorno, 2003, p. 81)

El énfasis que ponen en estos aspectos del relato tiene por objeto subrayar que Odiseo sobrevive porque se distancia de las potencias exteriores y de sí mismo. Las niega para auto-afirmarse y reorganizarlas bajo su control, pero para ello implícitamente renuncia a sí mismo, al mundo y a los otros. Bajo el imperativo práctico de supervivencia abandona un tipo de vinculación y “(...) sacrifica lo viviente en sí, para salvarse como un sí mismo endurecido" (Wiggershaus, 1986, p. 368).

En dicha negación y reorganización se realiza una violencia sobre la naturaleza externa e interna, expresada primero en la ruptura y después en la reconfiguración de lo otro como disponible para la autoafirmación del ser humano sobre ello. En esta línea:

(n)o sólo en la historia sino (también) en la constitución actual del ser humano es necesario reconocer, afirman Horkheimer y Adorno, un "acto de violencia que les sobreviene por igual al ser humano y a la naturaleza", una violencia mediante la cual "lo humano se auto-constituye al destacarse y "desprenderse", al trascender lo que a partir de ahí resulta ser "lo otro". (Echeverría, 2012, p. 47)

Por ello, a la luz de Odiseo, el proceso de distanciamiento y olvido de pertenencia cobra una nueva dimensión, pues la distancia permite un emplazamiento de los otros y de sí mismo que resulta identificable hasta la actualidad. En esta distancia se involucra el aprendizaje de emplazar a lo otro para dominarlo, y la separación del vínculo orgánico del sí mismo con el mundo.

Los episodios narran peligros, astucia, escapatoria, y de la renuncia autoimpuesta, por la que el yo aprende a dominar el peligro, obtiene su propia identidad y al mismo tiempo se despide de la dicha del arcaico ser-uno con la naturaleza tanto externa como interna. (Habermas, 1981a, p. 133) 
Al interior de este proceso, el distanciamiento se torna en separación radical y el olvido de pertenencia en negación de la naturaleza interna y externa, ambos elementos incrementan progresivamente su intensidad conducidos por la autoconservación.
Asimismo, el olvido de pertenencia a la naturaleza se ve reformado con el término negación y destrucción del sujeto, pero en esta nueva intensidad del término permanece la estructura del argumento respecto al ocultamiento del criterio funcional.

\section{(...) con la negación de la naturaleza en el ser humano se torna confuso y oscuro no sólo el telos del dominio de la naturaleza exterior, sino también el de la propia vida. En el momento en que el ser humano se amputa la conciencia de sí mismo como naturaleza, todos los fines por los que se mantiene en vida: el progreso social, el incremento de todas las fuerzas materiales e intelectuales, incluso la conciencia misma, pierden todo valor. (Horkheimer/Adorno, 2003, p. 78)}

Un contexto de ofuscación surge como elemento adicional y se entiende como consecuencia del olvido de vinculación. Esto es así porque el distanciamiento vuelto negación de la naturaleza en sí mismo implica un proceso de fragmentación de las relaciones cualitativas con el mundo y consigo mismo. Esto convierte al ser humano en agente de su propia subordinación como medio de la finalidad de autoconservación, como dominio de sí mismo. Para Horkheimer y Adorno:

\section{(...) la intronización del medio} como fin, que en el capitalismo tardío adquiere el carácter de abierta locura, es perceptible ya en la prehistoria de la subjetividad. El dominio del humano sobre sí mismo, que fundamenta su auto-conciencia, es virtualmente siempre la destrucción del sujeto, en cuyo servicio ella acontece, pues la sustancia dominada, oprimida y disuelta por la auto-conservación no es otra cosa que lo viviente, en función de lo cual sólo se determinan los resultados de la auto-conservación. (Horkheimer/ Adorno, 2003, pp. 61-62)

La continuidad del proceso de negación del sujeto que revelan los autores, en realidad pone de relieve la auto-subordinación implícita en el tipo de enfrentamiento asociado a la auto-conservación. Este proceso de separación y ahora negación de la naturaleza requerido en la medida que avanza histórica e institucionalmente la penetración del principio de auto-conservación, Adorno y Horkheimer lo llaman socialización 
radical, y de ello nuevamente pero también el industrial solitario consideran que da cuenta Odiseo, Robinson.

Por ello pertenece a la socialización universal, tal como la esbozan el viajero Odiseo y el fabricante solitario Robinson, ya originalmente la absoluta soledad que se manifiesta al final de la era moderna. Socialización radical quiere decir alienación radical. (...) Ambos lo logran sólo completamente separados de todos los otros humanos. Éstos se les presentan sólo en forma alienada: como enemigos o como puntos de apoyo, siempre como instrumentos, cosas. (Horkheimer/Adorno, 2003, p. 86)

Representar a los otros bajo el criterio instrumental es consecuencia de la desvinculación que ahora observamos en la forma de la separación completa que ejemplifican los autores con Robinson y Odiseo, pero al mismo tiempo es condición de un comportamiento inscrito en las convenciones del pensamiento ilustrado, en tanto

conducido por la reorganización del mundo como ente administrado.

En tal comportamiento, los elementos de la relación interhumana resultan incorporados a la noción de naturaleza sometida en un doble aspecto, por una parte tenemos el auto-sometimiento de la naturaleza propia y por otra, el sometimiento del otro. Para los autores:

El dominio (de la naturaleza) no se paga sólo con la alienación de los seres humanos respecto de los objetos dominados: con la reificación del espíritu fueron hechizadas las mismas relaciones entre los seres humanos, incluso las relaciones de cada individuo consigo mismo. Éste se convierte en un nudo de reacciones y comportamientos convencionales, que objetivamente se espera de él. (...) el industrialismo reifica las almas. (Horkheimer/Adorno, 2003, pp. 50-51)

En esta argumentación, una vez establecido el dominio de la naturaleza como fundamento, la objetivación surge como consecuencia de la secuencia de actos de control calculador. La capacidad de control sobre la naturaleza externa otorga el impulso para extender el control sobre la humanidad, porque el proceso de subordinación es incorporado de tal manera que todo enfrentamiento está inscrito bajo este patrón vuelto convención práctica. Como señala Honneth: 
Adorno y Horkheimer están convencidos de que este acto original de subsumir los procesos naturales bajo el esquema de actuación del control técnico, esto es, de la dominación de la naturaleza, proporciona el impulso necesario al proceso de auto-negación humana; es decir, esta objetivación de la naturaleza orientada en términos instrumentales corre pareja con el proceso de auto objetivación de la humanidad. (Honneth, 1985, p. 65)

Precisamente, esta forma de relación con los otros y consigo mismo se convierte en convención porque detrás del comportamiento esperado se incorpora una estructura de enfrentamiento determinada por el modo en que se habituó el trato previo con la naturaleza externa, pues:

\section{(...) en la medida en que los sujetos humanos incrementan sistemáticamente su control instrumental sobre la naturaleza externa, al mismo tiempo pierden de manera paulatina su natu- raleza interna, habida cuenta de que ésta tiene que ser tratada de la misma manera que aquélla. (Honneth, 1985, pp. 65-66)}

Esta incorporación práctica aparece bajo la forma de una consecuencia de la distancia que rompe con un tipo de enfrentamiento previo con la naturaleza interna y externa, y lo reemplaza rutinariamente desde los requerimientos instrumentales. Así observamos que el comportamiento ante la naturaleza genera una correspondencia con la dominación social porque se reproduce en el enfrentamiento consigo mismo y con los otros.

En un segundo nivel, además, podemos observar que Odiseo revela bajo el tipo de enfrentamiento consigo y con los otros una potestad o poder-sobre. Lo anterior resulta coherente con la frase que primero aparece en Dialéctica de la ilustración, "la dominación sobre la naturaleza se reproduce dentro de la humanidad" (Horkheimer/Adorno, 2003, p.133), y que posteriormente Horkheimer reformulará ligeramente en las lecciones publicadas bajo el título: Crítica de la razón instrumental como "El dominio de la naturaleza incluye el dominio sobre los humanos" (Horkheimer, 1991, p. 94). En ambas versiones de la frase el poder-sobre se unifica en dos ámbitos: la dominación de la naturaleza se reproduce dentro de la relación interhumana $y$, a su vez, en ella se instituye la dominación de la naturaleza externa e interna. Ambas versiones de la frase permiten identificar el punto en 
común "en la disposición del sujeto sobre la naturaleza objetivada y en el dominio de un sujeto que hace a otro sujeto o a sí mismo en objeto, la misma estructura de ejercicio de poder se repite" (Habermas, 1981a, p. 508). Esta misma estructura de ejercicio de poder-sobre muestra el elemento de una convención o rutina funcional como la base que permite la continua reorganización instrumental del mundo, pues hace posible un ejercicio de control ampliado sobre la naturaleza, sobre los demás y sobre sí mismos.

La estructura de ejercicio de poder incluye tres componentes implícitos, estos son control, mando y represión. Cada uno de ellos indica el ejercicio de poder-sobre referido a cada ámbito de enfrentamiento formulado bajo la noción de naturaleza externa e interna. El control refiere al ejercicio de poder-sobre el mundo material y simbólico, el mando refiere al ejercicio de poder-sobre los otros, y la represión refiere al ejercicio de poder-sobre sí mismo. Como señala Habermas, para Horkheimer y Adorno la idea de dominio no es una metáfora sino que expresa una noción sucinta de ejercicio de poder, pues: “(...) colocan al control sobre la naturaleza externa, al mando sobre los humanos y a la represión de la propia naturaleza interna bajo el título ‘dominación' en el mismo denominador" (Habermas, 1981a, p. 508).
Por otra parte, existe un elemento implícito entre el desenmascaramiento de la estructura de ejercicio de poder-sobre como control, mando y represión contenidos en la relación de enfrentamiento, y la idea de un proceso de reorganización funcional que hace del mundo un "ente administrado" (Horkheimer/Adorno, 2003, p. 62), que no es fácil de deducir directamente del argumento. En este sentido, el dinamismo que Horkheimer y Adorno pretenden revelar parte de la idea de una separación progresiva de sí mismo y de los otros dentro de la presión por el control de la naturaleza, el mando de los otros y la represión de sí mismo, porque en ella el ser humano se separa también de sus capacidades de transformar la forma de pensamiento y enfrentamiento instituida.

Así pues, la idea de dominio como control, mando y represión expone con mayor claridad las capacidades que el ser humano desplaza hacia el proceso funcional. Pues al incorporar rutinariamente el principio de auto-conservación, la auto-subordinación de sí mismo y la subordinación del otro implican un desplazamiento de capacidades como característica instituida en la forma de enfrentamiento. En este sentido, podemos observar que el argumento crítico revela la incorporación de una forma de relación 
al modo de una segunda naturaleza. En los términos de la interpretación de Habermas: "(l)a historia, en el momento de su manifiesta acelera- ción, fue congelada en naturaleza, se había desvanecido en el calvario de una esperanza tornada irreconocible" (Habermas, 1985, pp.141-142).

\title{
4. Capitalismo como aceleración y restricción crítica
}

Asimismo, siguiendo a Echeverría, considero que el argumento crítico revela que la auto-conservación cobró autonomía al ser incorporada como esquema de comportamiento, lo que convirtió al ser humano en medio de su realización. En consecuencia, la incorporación del principio de auto-conservación subordinó cualquier otra alternativa de enfrentamiento con el mundo y consigo mismo.

\begin{abstract}
(...) el destino de la ilustración occidental o moderna comenzó a tener vigencia cuando el sujeto se desentendió de la administración del cosmos, (...) cosificándola como una función que dejaba de requerir de su intervención y pasaba a cumplirse casual o "automáticamente" en el entrecruzamiento de la infinidad de procesos de realización de valor de los bienes convertidos en mercancías. Esta cosificación o cesión de sujetidad, esta merma de autarquía política es el sacrificio, similar al del comportamiento mágico-mítico, que hace el sujeto ilustrado en la época precapitalista de la modernidad (...). (Echeverría, 2012, pp. 54-55) ${ }^{18}$
\end{abstract}

El destino fue la automatización de un proceso funcional que ya no dependía de la conducción humana, como condición para conservar la auto-afirmación sobre la naturaleza externa e interna. La potestad estaba garantizada sobre lo otro en la medida en que la forma de control, mando y represión fue incorporada como ejercicio de poder de la forma de enfrentamiento dominante. En este sentido:

(...) el sujeto humano tomó un camino que lo ha llevado paradójicamente, de estar sometido bajo un poder ubicado en lo otro, en el caos, en la naturaleza salvaje, a estar sometido a un poder equivalente, pero ubicado ahora en él mismo; en él, como sujeto que salvaguarda al fin plenamente su identidad al cosificarse (...). (Echeverría, 2012, p. 56). 
Este proceso de formación o habituación social dentro de una forma de pensamiento y enfrentamiento cobra en el capitalismo un despliegue muy amplio, porque la intersección entre la mediación de los seres humanos por la mercancía y la forma de relación que determina extiende continuamente la forma de enfrentamiento contenida, y “(...) el intercambio de mercancías asume la función de un médium social que extiende a toda la sociedad un modelo de racionalidad formado en el proceso originario de auto-afirmación humana opuesto a la naturaleza externa" (Honneth, 1985, p. 26).

Los autores descubren, en la mercancía como mediación entre seres humanos, un proceso de configuración que en este caso extiende una forma de pensamiento y de enfrentamiento, pero "en modo alguno derivaron como Lukács (y Sohn-Rethel) la forma de pensamiento de la forma mercancía (...) no obstante, obtiene (el pensamiento instrumental) debido a la diferenciación del medio valor de cambio su significado universal" (Habermas, 1981a, pp. 506-507). La forma de pensamiento no es derivada de la estructura de la mercancía, sino que es el vehículo a través del cual son configurados rutinariamente los seres humanos en una forma de enfrentamiento. Este punto revela un aspecto crucial propio de la mercancía en tanto contiene una dimensión de vínculo social, además de contener un proceso oculto de producción social basado en relaciones asimétricas.

De este modo, el proceso funcional en el que inicialmente se inserta el ser humano, por medio de la habituación dentro de la forma de entendimiento calculador y la forma de enfrentamiento asociado, adquiere la figura dominante de la institucionalidad capitalista. Pues los procesos de emplazamiento subordinado de lo otro entran ahora como elemento al servicio de la reproducción de una forma de organización social. En este sentido:

El proceso técnico en el que el sujeto se ha reificado (...) está libre de la ambigüedad del pensamiento mítico como de todo significado en sí, pues la razón misma se ha convertido en simple medio auxiliar del aparato económico omnicomprensivo. (Horkheimer/Adorno, 2003, p. 53)

La integración del ser humano -como medio- en un proceso funcional de configuración del mundo y de sí mismo, lo releva de intervenir en una forma de configuración distinta. Por ello, la siguiente frase de Adorno y Horkheimer -en la parte final del ensayo sobre el concepto de ilustración- reviste un carácter de sentencia conclusiva en su diagnóstico crítico. Esto es: 
(S) u reducción a puros objetos del ente administrado que prefigura (pre-forma) a cada sección de la vida moderna incluyendo al lenguaje y la percepción, aparenta para ellos la necesidad objetiva contra la cual no se creen capaces (de poder hacer algo). (Horkheimer/Adorno, 2003, p. 62)

Desde la sentencia anterior, podemos observar como cobra fuerza un nivel de crítica más fundamental, donde ya no se trata de una aporía en el potencial racional del concepto, sino que debido a que la razón es convertida en mero medio del proceso económico ocurre un vaciamiento en su capacidad crítica. Con ello, lo que en un primer momento era considerado una aporía es dejado a un lado. Como indica Echeverría, la peculiaridad de la desgracia que Adorno y Horkheimer finalmente revelan "está en que la barbarie en que ha desembocado (la ilustración) no se debe a una 'decadencia' de su principio civilizatorio (...) sino precisamente a lo contrario, al despliegue más pleno de ese principio" (Echeverría, 2012, p. 44). Por ello, la justificación que le confería validez a este procedimiento reflexivo queda excluida, pues la incorporación del fin de auto-conservación en el modo de entendimiento y en el modo de enfrentamiento ha suprimido cualquier intento crítico.

En este punto la crítica abandona la aporía entre el potencial racional y los elementos contrarios a ella que la forma del pensamiento ilustrado conlleva, “(...) ahora es la razón misma la que se vuelve sospechosa de la terrible confusión entre pretensiones de poder y validez" (Habermas, 1985, p. 144). La razón es situada como objeto de crítica y su validez es puesta en cuestión junto con el potencial racional que inicialmente aparece en las instituciones de la modernidad. Ello hace que la crítica extienda la sospecha hasta su propio fundamento. "Este es el paso que efectúa la Dialéctica de la ilustración; ella independiza la crítica incluso frente a los propios fundamentos" (Habermas, 1985, p. 141). En estos términos culmina el proceso crítico hacia la forma de pensamiento y la forma de enfrentamiento asociada que revelan los autores en la ilustración.

Finalmente, en el último paso posible para una crítica que se ha vuelto contra aquello que le permite actuar -para una crítica que coloca a la razón misma como su objeto de desenmascaramiento- Horkheimer y Adorno revelan que la razón se ha asimilado al poder en tanto se ha convertido en un instrumento de control subordinado a la finalidad de auto-conservación actualizada en el aparato económico omnicomprensivo propio de la modernidad capitalista. Esto implica que los 
criterios de validez -que aunque de manera distorsionada eran aún patentes en el potencial racional del carácter aporético del pensamiento Ilustrado- sean desarticulados por un criterio funcional bajo el que ahora se reduce a la razón a medio auxiliar. Al mismo tiempo que ha incluido en su estructura de representación de lo otro un proceso de distancia, ruptura y ocultamiento que excluye a la necesidad de justificación desde el criterio de utilidad para el fin mencionado.

Con el concepto de "razón instrumental" Horkheimer y Adorno quieren sacar las cuentas a un entendimiento calculador que ha usurpado el puesto de la razón. (...) La razón, en tanto razón instrumental, se ha asimilado al poder, renunciando con ello a su fuerza crítica; ésta es la última revelación de una crítica ideológica aplicada ahora a sí misma. (Habermas, 1985, p. 144)

Las consecuencias de este argumento crítico -para la crítica que Dialéctica de la ilustración define dentro de la tradición de la Escuela de Frankfurt- son una toma de distancia de la idea de una crítica inmanente, pues rompe con la posibilidad de mantener la tensión entre el potencial racional que se encuentra dentro de la aporía del pensamiento ilustrado. Sin embargo, recupera una forma de negación determinada que pretende ya no más liberar el potencial racional, sino que se restringe a develar las pretensiones de poder-sobre en los conceptos.

La sospecha de ideología se torna total, pero sin cambiar de dirección. Se vuelve no solamente contra la función irracional de los ideales modernos, sino contra el potencial de razón de la propia cultura burguesa, y se extiende con ello a los fundamentos de una crítica ideológica de procedimiento inmanente; pero permanece la intención de conseguir un efecto de desenmascaramiento. (Habermas, 1985, p. 144)

Esto es, la crítica se vuelve total porque no pretende revelar más algún elemento normativo que ofrezca un criterio alternativo, "(...) la crítica que se ha vuelto total no tiene inscrita la dirección (normativa)" (Habermas, 1985, p. 145). La sola revelación o desenmasca- ramiento es lo único posible, el potencial normativo está ya disuelto y todo criterio alterno será imbuido por el proceso funcional. Pues el argumento deshace los fundamentos de una crítica inmanente porque su crítica implica a la razón misma. Para Habermas, este modo 
de negación determinada supone

abandonar la aporía -lo que él llama la contradicción performativa- ${ }^{-19}$ siempre latente.

\begin{abstract}
Horkheimer y Adorno encuentran otra opción, en la cual fomentan y mantienen abierta la contradicción performativa de una crítica ideológica que se excede a sí misma, pero que no quieren ya superarla teóricamente. Después de que, alcanzado tal nivel de reflexión, cada intento por poner en pie una teoría debería resbalar al vacío, renuncian a la teoría y practican ad hoc la negación determinada, se oponen con ello a cada fusión entre razón y poder. (Habermas, 1985, p. 154)
\end{abstract}

Renuncian a todo desarrollo teórico y consideran que sólo es posible permanecer en la aporía revelándola constantemente. $\mathrm{El}$ presupuesto bajo el que este tipo de crítica permanece considera que la aporía no tiene alternativa, pues en el momento en que la alternativa aparezca la aporía sería deshabilitada y un criterio que no queda preso en la aporía abriría nuevamente la posibilidad de la crítica inmanente, no obstante, a lo largo de las obras posteriores, sobre todo de Adorno, el argumento crítico permaneció en este modo de negación determinada.

\title{
5. A modo de conclusión
}

Como observamos a lo largo de este ensayo, Dialéctica de la ilustración puede ser interpretada como una crítica de las aporías en los criterios evaluativos que la sociedad moderna ha establecido para sí misma. Esta crítica procede de modo inmanente porque su instancia de validez se basaba en el propio contenido normativo del concepto investigado. Horkheimer y Adorno llamaron a dicha crítica negación determinada, en tanto se trata de un procedimiento que investiga las aporías al interior de las nociones en relación con lo que las define fundamentalmente, $y$ en relación a sus usos actualizados históricamente.

La crítica a la modernidad capitalista que puede desprenderse de Dialéctica de la ilustración ocurre precisamente si conjugamos el nuevo fundamento crítico basado en las estructuras del pensamiento con la idea de que la forma mercancía: a) extiende como nunca antes la forma de pensamiento y enfrentamiento propio de la modernidad; b) reproduce con mayor intensidad un trato instrumental asociado al progresivo predominio del intercambio; y c) depende como ninguna 
otra institución del pensamiento calculador, y del tipo de enfrentamiento y ejercicio de poder-sobre, como el revelado por los autores.

La crítica a la modernidad capitalista prosigue asimismo desde lo que Horkheimer y Adorno llaman el proceso funcional de la sociedad como ente administrado y la sociedad articulada por procedimientos administrativos que se reproducen como un sistema a través de los seres humanos pero al margen de su determinación. En este sentido, el argumento de Dialéctica de la ilustración se desarrolla desde la idea que el ser humano ha sido reducido a un medio del proceso de la sociedad administrada y del aparato económico omniabarcante a partir del predominio de la forma de pensamiento y de enfrentamiento de la ilustración. Su condición de medio lo releva de cualquier intervención para determinar la finalidad de autoconservación, y la habituación dentro de las rutinas de comportamiento y vinculación instrumental aseguran la permanencia del estado reducido del ser humano. Como argumenté, la segunda naturaleza indicaba una configuración tal de la vida humana, incluso del lenguaje y de la representación, que reduce al ser humano a un medio para la reproducción social de la modernidad capitalista.

Finalmente, los alcances de la crítica al capitalismo encuentran su límite al no contar con ningún criterio alternativo que escape a la omnipre- sencia del entendimiento calculador y el enfrentamiento instrumental. El pensamiento mismo es vaciado de su capacidad crítica en la medida en que sus procedimientos y conceptos quedan configurados como medios auxiliares de la auto-conservación. Asimismo, al dominar un tipo de pensamiento y de enfrentamiento que reproduce el proceso funcional de la articulación social capitalista representada como ente administrado, la crítica queda presa de una contradicción porque no tiene los recursos para sustentar criterios que sean capaces de conservar su integridad y oponer resistencia.

La conclusión del propio argumento crítico, al calificar al proceso como omniabarcante, hace que resulte imposible mantener la idea de un criterio que escape a la influencia determinante de la dinámica del ente administrado, y de la forma de pensamiento y enfrentamiento. Por ello, la conclusión que alcanza Dialéctica de la ilustración es que una vez que esta forma de pensamiento y enfrentamiento han configurado del tal modo la vida humana es posible mostrar sus distorsiones, pero no así desarrollar un criterio alternativo. Sólo una crítica inmanente ad casum que no tenga más propósito que desenmascarar las pretensiones de poder al interior de los conceptos es viable, debido a que la crítica no tiene capacidad de inscribir en su procedimiento una dirección normativa alterna, pues sus propios recursos han quedado comprometidos. 


\section{Referencias}

- Benhabib, S. (1986). Critique, Norm and Utopia. A study of the Foundations of Critical Theory. New York: Columbia University Press.

- Echeverría, B. (2012). Modernidad y blanquitud. México: Era.

- Habermas, J. (1998). Die postnationale Konstellation. Frankfurt am Main: Suhrkamp.

. (1985). Der philosophische Diskurs der Moderne. Frankfurt am Main: Suhrkamp.

(1981a). Theorie des kommunikativen Handelns. Handlungsrationalität und gesellschaftliche Rationalisierung. Band 1. Frankfurt am Main: Suhrkamp.

. (1981b). Theorie des kommunikativen Handelns. Zur Kritik der funktionalistischen Vernunft. Band 2. Frankfurt am Main: Suhrkamp.

- Hegel, G. W. F. (1981). Die subjektive Logik (1816). Bd.12 in Gesammelte Werke. Hamburg: Felix Meiner Verlag.

. (1980). Phänomenologie des Geistes. Bd. 9 in Gesammelte Werke. Hamburg: Felix Meiner Verlag.

. (1968). Jenaer kritische Schriften. Bd. 4 in Gesammelte Werke. Hamburg: Felix Meiner Verlag.

- Held, D. (1980). Introduction to Critical Theory. Horkheimer to Habermas. Berkley: University of California Press.

- Honneth, A. (2000). Das Andere der Gerechtigkeit. Aufsätze zur praktischen Philosophie. Frankfurt am Main: Suhrkamp. - (1985). Kritik der Macht: Reflexionsstufen einer kritischen Gesellschaftstheorie. Frankfurt am Main: Suhrkamp.

- Horkheimer, M. (1991). Zur Kritik der Instrumentellen Vernunft. Bd. 6 in Gesammelte Schriften. Frankfurt am Main: Fischer.

- Horkheimer, M. und Adorno, T. W. (2003). Dialektik der Aufklärung. Philosophische Fragmente. Bd. 5 in Gesammelte Schriften,. Frankfurt am Main: Fischer.

- Horstmann, Rolf-Peter. (2004). Die Grenzen der Vernunft. Frankfurt am Main: Vittorio Klostermann Verlag.

- Lukács, G. (1968). Geschichte und Klassenbewusstsein. Berlin: Luchterhand. 
- Marx, K. (2006). Ökonomische Manuskripte 1857/58. Grundrisse der Kritik der politischen Ökonomie. In Marx-Engels-Gesamtausgabe (MEGA) II/1. Berlin: Akademie Verlag.

. (1989). Das Kapital, Kritik der politischen Ökonomie, Erster Band, Hamburg 1883. In Marx-Engels-Gesamtausgabe (MEGA) II/8. Berlin: Dietz Verlag.

- Wellmer,A. (1973). Kritische Gesellschaftstheorie und Positivismus. Frankfurt am Main: Suhrkamp.

- Wiggershaus, R. (1986). Die Frankfurter Schule. Geschichte, Theoretische Entwicklung Politische Bedeutung. München/Wien: Carl Hanser Verlag.

\section{Notas}

1 Aldo Rabiela Beretta es doctor en filosofía por la Universidad Nacional Autónoma de México. Fue miembro del seminario de investigación de filosofía social de la profesora Rahel Jaeggi en la Humboldt Universität de Berlín (20122014). Actualmente es colaborador científico y docente de la Universidad Alice Salomon en Berlín.

2 Salvo las referencias que corresponden a la obra de Bolívar Echeverría, los pasajes citados a lo largo de este ensayo son traducciones propias elaboradas con base en los textos originales, según la edición indicada en el aparato bibliográfico.

3 Cfr. Habermas, (1985, p. 130).

4 Cfr. Habermas, (1985, pp. 130-131).

5 Cfr. Honneth, (2000, pp. 70-88).

6 La más reciente publicación de los MarxEngels-Gesamtausgabe (MEGA) coloca al "Cuaderno M" dentro de los Manuscritos económicos de 1857/1858, como apartado A) bajo el título "Introducción" (Einleitung). Cfr. Marx (2006, pp. 21-45). Sobre la génesis de la publicación de la "Introducción" contamos con una traducción al castellano del estudio de Umberto Curi, "La crítica marxiana de la economía política en la Einleitung”, que aparece en la decimoquinta edición de la Introducción general a la crítica de la economía política publicada por Siglo XXI. Cfr. Marx (2006, pp. 9-30).

7 Cfr. Marx (2006, p. 41).

8 Cfr. Wellmer (1973, p.138).

9 Cfr. Horkheimer und Adorno (2003, p. 276).

10 Cfr. Wiggershaus (1986, p. 365).

11 Cfr. Held, (1980, p. 152).

12 Cfr. Horkheimer und Adorno, (2003, p. 35). La mención a Hegel se refiere a Gesammelte Werke, Bd. 9. Phänomenologie des Geistes, p. 305.

13 Cfr. Marx (1989, pp. 73-78).

14 Cfr. Habermas, (1981a, p. 506).

15 Existen dos puntos de vista sobre la interpretación de la dominación de la naturaleza expresados en Dialéctica de la ilustración. Por un lado, tenemos la interpretación de Habermas que sostiene que cuando Adorno y Horkheimer colocan esta forma de pensamiento en la prehistoria de la subjetividad desarrollan un tipo de argumento enmarcado en una filosofía de la historia, apoyados en presupuestos metafísicos ya superados. En contraste, tenemos la reciente interpretación de Honneth, quien ha sugerido que Dialéctica de la 
ilustración desarrolla una crítica develadora, por lo que el recurso interpretativo no tiene el propósito de dar una explicación alternativa a la historia de la especie, sino revelar elementos ocultos en el concepto de ilustración. Por ello, el uso respecto al término naturaleza es implementado como metáfora para referirse al mundo en su carácter material y simbólico, y al ser humano.

16 Cfr. Horkheimer und Adorno, (2003, p. 104).

17 Particularmente reconocemos la influencia de los siguientes apartados correspondientes al corpus hegeliano: a) "Glauben und Wissen oder die Reflexionsphilosophie der Subjektivität in der Vollständigkeit ihrer Formen als Kantische, Jacobische und Fischteiche Philosophie", especialmente en su sección dedicada a Kant, en Hegel (1968, pp. 325-346), de: b) la sección dedicada al juicio, en Hegel (1981, pp. 53-89), y de: c) el apartado titulado "Der Kampf der Aufklärung mit dem Aberglauben" en Hegel (1980, pp. 293-311).
18 Las cursivas son mías. Es importante señalar que los verbos desentender y ceder que Echeverría utiliza para describir la acción del ser humano en la ilustración moderna no refieren a un proceso de actividad voluntaria, sino que describen la expresión de un comportamiento configurado por las condiciones de la modernidad capitalista.

19 El concepto de contradicción performativa que aparece en las lecciones compiladas en Der philosophische Diskurs der Moderne, particularmente en Die Verschlingung von Mythos und Aufklärung: Horkheimer und Adorno, significa para Habermas una incompatibilidad entre el contenido de una afirmación y los presupuestos teórico-racionales implícitos en ella. En este caso, la contradicción performativa en Adorno y Horkheimer indicaría que su crítica hacia el concepto de razón instrumental es de tal envergadura que se habrían quedado sin asidero (racional) para ejercerla. Cfr. Habermas, (1985, pp. 130-157). 